\title{
Incidence of interface fluid syndrome after laser in situ keratomileusis in Egyptian patients
}

\author{
This article was published in the following Dove Press journal: \\ Clinical Ophthalmology \\ 4 April 2017 \\ Number of times this article has been viewed
}

\author{
Amr A Gab-Alla \\ Ophthalmology Department, Faculty \\ of Medicine, Suez Canal University, \\ Ismailia, Egypt
}

Purpose: To determine the incidence of interface fluid syndrome (IFS) secondary to steroid-induced elevation of intraocular pressure (IOP) following laser in situ keratomileusis (LASIK) in myopic Egyptian patients.

Methods: This retrospective case series study was conducted at El-Gowhara Private Eye Center. The medical records of 1,807 patients (3,489 eyes), who underwent LASIK to correct myopia from April 2012 to December 2015 were included. The patients were operated on and reviewed by one surgeon (AAG) for IFS after LASIK associated with elevation of IOP (as compared to preoperative values).

Results: This paper reports the incidence of 2.9\% (54 patients) (102 eyes) of IFS induced by increased IOP after LASIK in Egyptian patients. The medical records of 1,807 patients (3,489 eyes) with mean age \pm standard deviation (SD) $26.4 \pm 2.7$ years, who presented with mean myopia $\pm \mathrm{SD}-4.50 \pm 1.3 \mathrm{D}$, mean astigmatism $\pm \mathrm{SD}-1.43 \pm 0.8$, mean $\mathrm{IOP} \pm \mathrm{SD} 15.2 \pm 1.2 \mathrm{mmHg}$, and mean central corneal thickness \pm SD $549 \pm 25.6 \mu \mathrm{m}$, were included. The preoperative anterior and posterior segments, corneal topography, and Schirmer's test were unremarkable.

Conclusion: Limiting topical steroids and routinely measuring the IOP post-LASIK are necessary steps to prevent IFS, especially in case of myopia. A high index of suspicion is required to make a diagnosis. High-resolution optical coherence tomography is helpful to confirm the diagnosis.

Keywords: LASIK, postoperative complication, diffuse lamellar keratitis, interface fluid, myopia

\section{Introduction}

Laser in situ keratomileusis (LASIK) is the most common surgery to correct refractive errors including myopia, hyperopia, and astigmatism. ${ }^{1}$ Topical corticosteroids are universally prescribed after LASIK, usually for 7-10 days (depending on the circumstances) to treat inflammatory processes. ${ }^{1}$

Alternatively, it is reported that a significant increase in intraocular pressure (IOP) occurs in 5\%-30\% of steroid users. ${ }^{2-4}$ Also, it typically occurs 2-6 weeks after steroid use, but it has also been recognized to occur within hours of steroid use in some patients. ${ }^{2-4}$ The risk factors associated with steroid response include glaucoma or a family history of steroid response. Moreover, $88 \%$ of patients with myopia $>5.00 \mathrm{D}$ have increased pressures with steroid use. ${ }^{5}$

The elevated IOP can cause aqueous humor to enter the cornea and collect at the interface under the corneal flap. This collection is termed interface fluid syndrome (IFS). ${ }^{6-8}$

Among interface complications, diffuse lamellar keratitis (DLK) is a well-defined condition in the literature (most common and the most common etiology mistaken
Correspondence: Amr A Gab-Alla Ophthalmology Department, Faculty of Medicine, Suez Canal University, Ring Road, Ismailia 4I522, Egypt Tel +20 I22 $283626 \mid$

Email amrophth@hotmail.com 
for other conditions), and there have been some reports of another entity that is clinically identical to DLK. This entity is called pressure-induced inter-lamellar stromal keratitis (PISK) or IFS. However, unlike DLK, stoppage of the corticosteroid drops resulted in its resolution, suggesting that this is a steroid-induced pressure phenomenon rather than an inflammatory reaction. ${ }^{9}$

Recently, Tourtas and Cursiefen ${ }^{10}$ created the term "pressureinduced stromal keratopathy (PISK)" which preserves the most common abbreviated term "PISK", which also precisely and most efficiently conveys the etiology of the condition.

IFS is the most commonly used term to define fluid collection at the interface under the corneal flap. ${ }^{7}$ It was first described by Lyle and Jin. ${ }^{8}$ Some authors use the term "pressure induced stromal keratitis" interchangeably. ${ }^{9}$ Early detection of interface fluid secondary to steroid-induced elevation of IOP, and differentiation from DLK is critical since prolonged use of steroids to treat the presumed DLK diagnosis will worsen the condition. ${ }^{11-13}$

So, the purpose of this study was to determine the incidence of IFS secondary to steroid-induced elevation of IOP following LASIK in myopic Egyptian patients.

\section{Patients and methods}

The medical records of 1,807 patients $(3,489$ eyes), who underwent LASIK to correct myopia from April 2012 to December 2015 at the El-Gowhar Eye Center in Ismailia, Egypt, who were operated on and reviewed by one surgeon (AAG), were included.

Preoperatively, patients underwent complete eye examinations, including slit-lamp examination, IOP with applanation tonometry, indirect fundoscopy, and corneal topography (Sirius; CSO, Florence, Italy). Snellen chart was used to measure uncorrected visual acuity and best spectaclecorrected visual acuity.

All eyes underwent LASIK using the $500 \mathrm{kHz}$ Amaris excimer laser (Schwind eye-tech-solutions, Kleinostheim, Germany). Flaps were cut using the Moria M2 microkeratome (Moria, Antony, France), and the corrected optical zones ranged from 5.8 to $7.0 \mathrm{~mm}$ in diameter. All eyes had routine procedures.

Postoperative treatment included topical application of tobramycin $3 \mathrm{mg} / \mathrm{mL}$ and dexamethasone $1 \mathrm{mg} / \mathrm{mL}$ five times per day for the first week, tapered to three times per day for the following 21 days, and sodium hyaluronate $0.15 \mathrm{~g}$ five times per day for 5 weeks. The patients were evaluated by complete ocular examinations on the first day, first week, fourth week, and sixth week postoperatively.
When patients complained of decreased vision with flap edema, IOP measurement by ocular response analyzer (ORA), anterior optical coherence tomography (OCT), and fundus examination (hardly seen in some patients) were done. In patients with IFS and elevated IOP, topical corticosteroids were discontinued, and topical anti-glaucoma medications were started with timolol maleate $0.5 \%$ twice daily. If a further topical medication was required, carbonic anhydrase inhibitors, alpha-2 selective adrenergic agonist, and prostaglandin derivatives were added until the IOP returned to preoperative levels. All the patients with IFS and elevated IOP were followed 6 months post-improvement.

This study adhered to the guidelines of the Declaration of Helsinki and was approved by the research ethics committee of the Faculty of Medicine, Suez Canal University. Informed written consent was obtained from all patients after explanation of LASIK procedures and the surgical technique. Because of the retrospective nature of the study design and the large number of patients, no informed consent was required to review the medical records. The confidentiality of the patients' data was ensured.

\section{Statistical analysis}

Data were imported into Statistical Package for the Social Sciences (SPSS version 20.0; IBM Corporation, Armonk, NY, USA) software for analysis. Baseline characteristics of the study population were presented as frequencies and percentages $(\%)$ or mean values and standard deviations (SDs). Differences between frequencies in the groups were compared by Chi-square test or Fisher's exact probability test of expected values. Differences between means in the groups were compared by Student's $t$-test or Mann-Whitney $U$ test according to the normality of data. A $P$-value of $<0.05$ was considered significant.

\section{Results}

Preoperatively, 1,807 patients (3,489 eyes) aged from 21 to 38 years (mean \pm SD $27.4 \pm 5$ years) presented with myopia ranging from -2.00 to $-7.00 \mathrm{D}$ (mean $\pm \mathrm{SD}-4.50 \pm 1.3 \mathrm{D})$, and astigmatism ranging from -1.00 to $-4.00 \mathrm{D}$ (mean \pm $\mathrm{SD}-1.43 \pm 0.8)$. IOP ranged between 14 and $18 \mathrm{mmHg}$ (mean $\pm \mathrm{SD} 15.2 \pm 1.2 \mathrm{mmHg}$ ). Central corneal thickness ranged from 514 to $580 \mu \mathrm{m}$ (mean $\pm \mathrm{SD} 549 \pm 25.6 \mu \mathrm{m}$ ). The anterior and posterior segments, corneal topography, and Schirmer's test were unremarkable. Table 1 shows the preoperative characteristics of all patients.

Postoperatively, 54 patients (102 eyes) (2.9\%) developed IFS secondary to IOP elevations between 17 and 36 days 
Table I Preoperative characteristics of all patients

\begin{tabular}{ll}
\hline Preoperative characteristics & Total patients \\
\hline Eyes $(\mathrm{n})$ & 3,489 \\
Age (years) & \\
$\quad$ Mean \pm SD & $27.4 \pm 5$ \\
$\quad$ Range & 21 to 38 \\
Sphere (D) & \\
$\quad$ Mean \pm SD & $-4.5 \pm 1.3$ \\
$\quad$ Range & -2.00 to -7.00 \\
Cylinder (D) & \\
$\quad$ Mean $\pm S D$ & $-1.43 \pm 0.8$ \\
$\quad$ Range & -1.00 to -4.00 \\
IOP (mmHg) & \\
$\quad$ Mean $\pm S D$ & $15.2 \pm 1.2$ \\
$\quad$ Range & 14 to 18 \\
Central corneal thickness $(\mu \mathrm{m})$ & \\
$\quad$ Mean $\pm S D$ & $549 \pm 25.6$ \\
Range & 514 to 580 \\
\hline
\end{tabular}

Abbreviations: SD, standard deviation; IOP, intraocular pressure.

after LASIK (mean \pm SD 19 \pm 4.2 days). This IFS group was aged between 23 and 34 years (mean \pm SD $26.2 \pm 4.2$ years). The best spectacle-corrected visual acuity decreased in all patients by $2-4$ lines. All eyes in the IFS group had myopia with spherical equivalent ranging from -0.75 to $-2.5 \mathrm{D}$ (mean $\pm \mathrm{SD}-1.5 \pm 0.6 \mathrm{D}$ ) and astigmatism ranging from -0.5 to $-1.5 \mathrm{D}$ (mean $\pm \mathrm{SD}-0.78 \pm 0.4$ ). IOP ranged between 28 and $43 \mathrm{mmHg}$ (mean $\pm \mathrm{SD} 35 \pm 3.4 \mathrm{mmHg}$ ), central corneal thickness ranged from 580 to $689 \mu \mathrm{m}$ (mean \pm SD $665 \pm 15.6 \mu \mathrm{m})$. Table 2 shows postoperative characteristics of IFS group (Figures 1 and 2).

There were no significant differences between preoperative characteristics of IFS group and control group (LASIK

Table 2 Postoperative characteristics of IFS group

\begin{tabular}{ll}
\hline Postoperative characteristics & IFS group \\
\hline Eyes $(\mathrm{n})$ & 102 \\
Age (years) & \\
$\quad$ Mean \pm SD & $26.2 \pm 4.2$ \\
$\quad$ Range & 23 to 34 \\
Sphere (D) & \\
$\quad$ Mean \pm SD & $-1.5 \pm 0.6$ \\
$\quad$ Range & -0.75 to -2.5 \\
Cylinder (D) & \\
$\quad$ Mean $\pm S D$ & $-0.78 \pm 0.4$ \\
$\quad$ Range & -0.5 to -1.5 \\
IOP (mmHg) & \\
$\quad$ Mean $\pm S D$ & $35 \pm 3.4$ \\
$\quad$ Range & 28 to 43 \\
Central corneal thickness $(\mu \mathrm{m})$ & \\
$\quad$ Mean \pm SD & $665 \pm 15.6$ \\
Range & 580 to 689 \\
\hline
\end{tabular}

Abbreviations: IFS, interface fluid syndrome; SD, standard deviation; IOP. intraocular pressure.

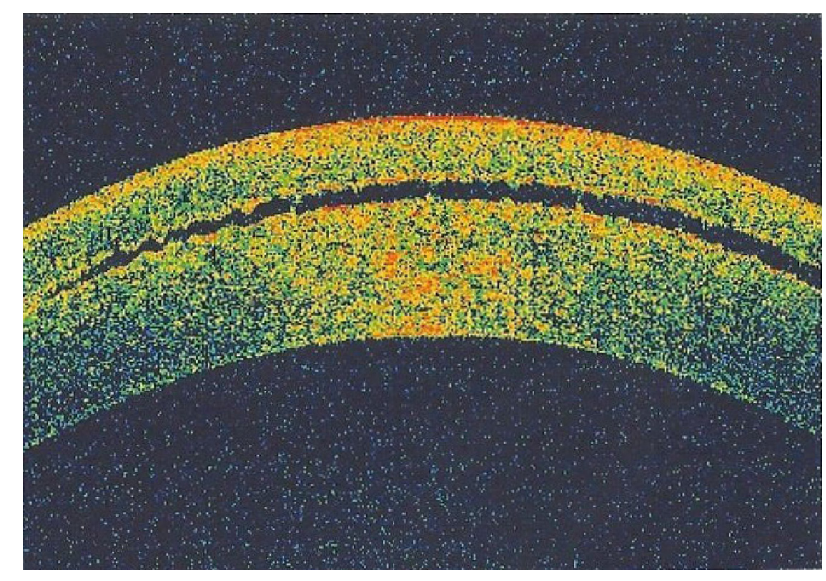

Figure I Anterior segment optical coherence tomography of the interface fluid as optical space between the corneal flap and the stroma.

patients who did not develop IFS) (Table 3). No cases with post-LASIK IOP elevations without interface fluid were recorded.

After cessation of topical steroids and use of topical anti-glaucoma medications, the IOP and uncorrected visual acuity returned to the expected values within 4-6 weeks of treatment. Flap edema and corneal haze disappeared after the IOP improved to normal levels.

\section{Discussion}

The LASIK interface is the potential space between anterior and posterior corneal lamellae, which is a new anatomical region in the cornea and came into existence with LASIK procedures. Within it, some biochemical processes take place after construction of the corneal flap, including limitation of corneal wound healing and intercellular reorganization. ${ }^{14}$ The anatomy of this interface permits a diversity of unusual complications to arise from different etiologies, often with similar clinical conditions. ${ }^{15}$

IFS is a relatively rapid steroid response resulting in high IOP with fluid accumulation in the corneal interface between corneal flap and stroma. The amount of this fluid may be relatively small, resulting in diffuse haziness without any obvious fluid, ${ }^{11}$ or it may be marked, with a visible fluid cleft separating the anterior flap from the stroma. ${ }^{12}$ IFS typically appears early after LASIK, but also many years after LASIK. Ortega-Usobiaga et a ${ }^{16}$ reported a case of IFS of the left eye after cataract surgery in a patient who had undergone previous LASIK surgery 10 years ago.

IFS appears to be a more complex condition to recognize than other interface complications due to unclear nomenclature in the literature, and the wide variety of presentations. 15 "Keratitis" is a misnomer in this condition, as 


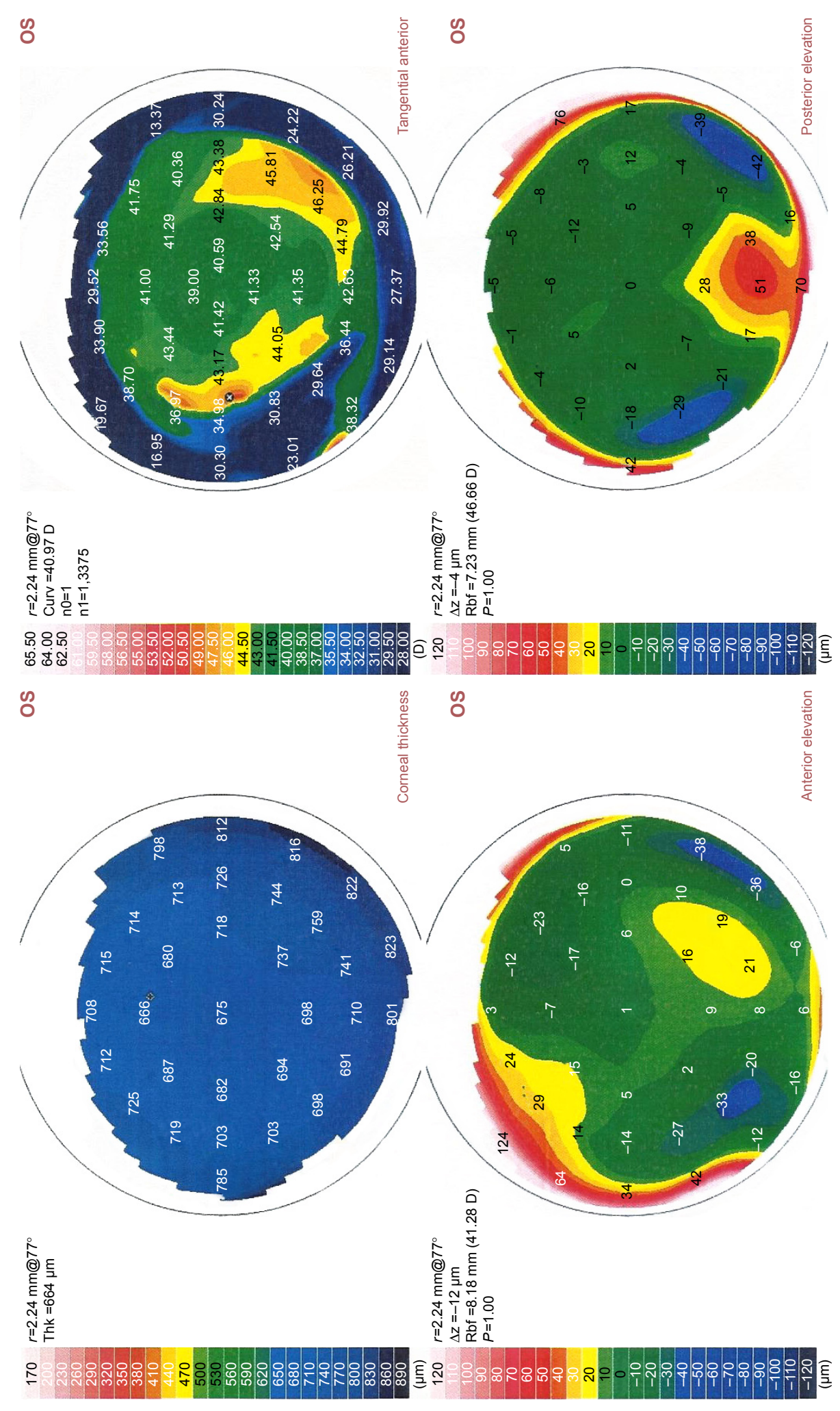

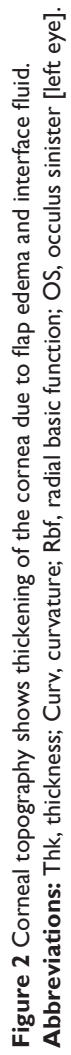


Table 3 Comparison between the preoperative characteristics of IFS group and control group (LASIK patients who did not develop IFS)

\begin{tabular}{llll}
\hline Preoperative characteristics & $\begin{array}{l}\text { IFS group } \\
\text { eyes, } \mathbf{n}(\%)=102 ~(2.9)\end{array}$ & $\begin{array}{l}\text { Control group } \\
\text { eyes, } \mathbf{n}(\%)=\mathbf{3 , 3 8 7}(\mathbf{9 7 . 1})\end{array}$ & 0.44 \\
\hline Mean age (years) \pm SD & $26.2 \pm 4.2$ & $26.6 \pm 5.2$ & 0.07 \\
Mean sphere (D) \pm SD & $-4.6 \pm 0.9$ & $-4.4 \pm 1.1$ & 0.06 \\
Mean cylinder (D) \pm SD & $-1.2 \pm 0.4$ & $-1.33 \pm 0.7$ & 0.13 \\
Mean IOP $(\mathrm{mmHg}) \pm$ SD & $15.3 \pm 2.1$ & $15.1 \pm 1.3$ & 0.1 \\
Mean central corneal thickness $(\mu \mathrm{m}) \pm$ SD & $529 \pm 0.3$ & $533 \pm 20.7$ & \\
\hline
\end{tabular}

Abbreviations: IFS, interface fluid syndrome; LASIK, laser in situ keratomileusis; SD, standard deviation; IOP, intraocular pressure.

in vivo confocal microscopic findings of interlamellar stromal keratopathy induced by elevated IOP have demonstrated that no actual keratocyte inflammation is present. ${ }^{17,18}$ IFS is technically correct. ${ }^{15}$

This study is the first to report the incidence of $2.9 \%$ IFS secondary to steroid-induced elevation of IOP following LASIK in myopic Egyptian patients. This may be due to the topical use of dexamethasone $0.1 \%$ post-LASIK, which is a potent steroid for preoperative topical use, or the genetic predisposition of the Egyptian patients (who may be high responders to steroids).

The high incidence of IFS in this series could have been influenced by the duration of the postoperative regimen of dexamethasone (1 month) and the dose (five times daily for the first week). Ortega-Usobiaga et a ${ }^{19}$ reported a very large series of LASIK treatments (55,255 patients) and postoperative regimen of dexamethasone $1 \mathrm{mg} / \mathrm{mL}$ three times a day for only 1 week.

No studies have reported the incidence of IFS following LASIK. There are only clinical manifestations of some recorded cases and of how to differentiate it from DLK.

The degree of the fluid accumulated in the corneal interface masks precise IOP measurements when measured using a Goldmann applanation tonometer (GAT). Real IOP is greater than IOP measured centrally, and peripheral measurements generate a more precise IOP. ${ }^{20}$ When the interface fluid is a small amount, IOP measurements may be elevated, but still low. However, with a larger amount of interface fluid clefts, IOP will measure very low due to the cushioning effect of this fluid. ${ }^{15}$

The measurement of IOP in a patient chronically using steroids after LASIK (more than 2 weeks) due to different causes is a critical issue, even in early postoperative cases. IOP measurement is artifactually reduced after routine LASIK $;{ }^{21}$ so, any increased IOP postoperatively deserves further investigation. Whenever IOP measurements are doubtful, different means should be tried to determine IOP; this includes rebound tonometry, ORA, dynamic contour tonometry or Schiotz. ${ }^{22-24}$ Previous reports on IFS recommended performing IOP measurement on the periphery of the cornea outside the edge of the corneal flap (no interface fluid), using the rebound tonometer ${ }^{20}$ to obtain a better estimate of the IOP. However, this may overestimate IOP due to the higher corneal thickness in the peripheral cornea. ${ }^{25}$

In conclusion, ophthalmologists are likely to face this condition, so limiting topical steroids and routinely measuring the IOP post-LASIK are necessary steps to prevent IFS, especially in myopic patients. A high index of suspicion is required to diagnose it, and it should be suspected when there is LASIK flap edema with low IOP measured by GAT. High-resolution OCT is helpful to confirm the diagnosis.

\section{Acknowledgments}

This research was presented at the 21st Winter Meeting of the European Society of Cataract and Refractive Surgeons (ESCRS) held at Maastricht/the Netherlands; February 10-12, 2017 as a poster. The abstract was published online in the meeting program.

\section{Disclosure}

The author reports no conflicts of interest in this work.

\section{References}

1. Pallikaris IG, Siganos DS. Excimer laser in situ keratomileusis and photorefractive keratectomy for correction of high myopia. J Refract Corneal Surg. 1994;10(5):498-510.

2. Clark AF. Basic sciences in clinical glaucoma: steroids, ocular hypertension, and glaucoma. J Glaucoma. 1995;4(5):354-369.

3. Becker B, Mills DW. Corticosteroids and intraocular pressure. Arch Ophthalmol. 1963;70:500-507.

4. Armaly MF. Effect of corticosteroids on intraocular pressure and fluid dynamics, the effect of dexamethasone in the normal eye. Arch Ophthalmol. 1963;70:482-491.

5. Tourtas T, Kopsachilis N, Meiller R, Kruse FE, Cursiefen C. Pressureinduced interlamellar stromal keratitis after laser in situ keratomileusis. Cornea. 2011;30(8):920-923. 
6. Kang SJ, Dawson DG, Hopp LM, Schmack I, Grossniklaus HE, Edelhauser HF. Interface fluid syndrome in laser in situ keratomileusis after complicated trabeculectomy. J Cataract Refract Surg. 2006; 32(9):1560-1562.

7. Waring GO 3rd. Appropriate term for post-LASIK corneal edema. J Cataract Refract Surg. 2009;35(8):1482-1483.

8. Lyle WA, Jin GJ. Interface fluid associated with diffuse lamellar keratitis and epithelial ingrowth after laser in situ keratomileusis. J Cataract Refract Surg. 1999;25(7):1009-1012.

9. Smith RJ, Maloney RK. Diffuse lamellar keratitis. A new syndrome in lamellar refractive surgery. Ophthalmology. 1998;105(9):1721-1726.

10. Tourtas T, Cursiefen C. "PISK-itis" or "PISK-opathy"? Cornea. 2012; 31(2):107.

11. Belin MW, Hannush SB, Yau CW, Schultze RL. Elevated intraocular pressure-induced interlamellar stromal keratitis. Ophthalmology. 2002;109(10):1929-1933

12. Hamilton DR, Manche EE, Rich LF, Maloney RK. Steroid-induced glaucoma after laser in situ keratomileusis associated with interface fluid. Ophthalmology. 2002;109(4):659-665.

13. Shaikh NM, Shaikh S, Singh K, Manche E. Progression to end-stage glaucoma after laser in situ keratomileusis. J Cataract Refract Surg. 2002;28(2):356-359.

14. Dawson DG, Kramer TR, Grossniklaus HE, Waring GO 3rd, Edelhauser HF. Histologic, ultrastructural, and immunofluorescent evaluation of human laser-assisted in-situ keratomileusis corneal wounds. Arch Ophthalmol. 2005;123(6):741-756.

15. Randleman JB, Shah RD. LASIK interface complications: etiology, management and outcomes. J Refract Surg. 2012;28(8):575-586.

16. Ortega-Usobiaga J, Martin-Reyes C, Llovet-Osuna F, Damas-Mateache B, Baviera-Sabater J. Interface fluid syndrome in routine cataract surgery 10 years after laser in situ keratomileusis. Cornea. 2012;31(6):706-707.
17. Cheng AC, Law RW, Young AL, Lam DS. In vivo confocal microscopic findings in patients with steroid-induced glaucoma after LASIK. Ophthalmology. 2004;111(4):768-774.

18. Kurian M, Shetty R, Shetty BK, Devi SA. In vivo confocal microscopic findings of interlamellar stromal keratopathy induced by elevated intraocular pressure. J Cataract Refract Surg. 2006;32(9):1563-1566.

19. Ortega-Usobiaga J, Llovet-Osuna F, Djodeyre MR, Llovet-Rausell A, Beltran J, Baviera J. Incidence of corneal infections after laser in situ keratomileusis and surface ablation when moxifloxacin and tobramycin are used as postoperative treatment. J Cataract Refract Surg. 2015;41(6): 1210-1216.

20. Goto S, Koh S, Toda R, et al. Interface fluid syndrome after laser in situ keratomileusis following herpetic keratouveitis. J Cataract Refract Surg. 2013;39(8):1267-1270.

21. Chang DH, Stulting RD. Change in intraocular pressure measurements after LASIK the effect of the refractive correction and the lamellar flap. Ophthalmology. 2005;112(6):1009-1016.

22. Park HJ, Uhm KB, Hong C. Reduction in intraocular pressure after laser in situ keratomileusis. J Cataract Refract Surg. 2001;27(2):303-309.

23. Fogla R, Rao SK, Padmanabhan P. Interface fluid after laser in situ keratomileusis. J Cataract Refract Surg. 2001;27(9):1526-1528.

24. Pepose JS, Feigenbaum SK, Qazi MA, Sanderson JP, Roberts CJ. Changes in corneal biomechanics and intraocular pressure following LASIK using static, dynamic, and noncontact tonometry. Am J Ophthalmol. 2007;143(1):39-47.

25. Lim Y, Yamaanari M, Fukuda S, et al. Birefringence measurement of cornea and anterior segment by office-based polarization sensitive optical coherence tomography. Biomed Opt Express. 2011;2(8):2392-2402.
Clinical Ophthalmology

\section{Publish your work in this journal}

Clinical Ophthalmology is an international, peer-reviewed journal covering all subspecialties within ophthalmology. Key topics include: Optometry; Visual science; Pharmacology and drug therapy in eye diseases; Basic Sciences; Primary and Secondary eye care; Patient Safety and Quality of Care Improvements. This journal is indexed on Submit your manuscript here: http://www.dovepress.com/clinical-ophthalmology-journal

\section{Dovepress}

PubMed Central and CAS, and is the official journal of The Society of Clinical Ophthalmology (SCO). The manuscript management system is completely online and includes a very quick and fair peer-review system, which is all easy to use. Visit http://www.dovepress.com/ testimonials.php to read real quotes from published authors. 